1. MBBS, FCPS

Women Medical Officer

Sindh Goverment Hospital Karachi.

2. MBBS, FCPS

Assistant Professor Obstetrics \&

Gynecology

PAQSJ Gambat Institute of Medical

Sciences Gambat,

Khairpur Sindh.

3. MBBS, FCPS

Senior Instructor Obstetrics \&

Gynecology

AKU Garden, Karachi

4. MBBS, FCPS

Trainner Medical Officer

PHDC (Provisional Health

Developmental Center) Jamshoro.

5. MBBS, FCPS

Senior Medical Officer

SINS Govt. Hospital Korangi

6. MBBS, FCPS

Assistant Professor Obstetrics \&

Gynecology

PAQSJ Gambat Institute of Medical

Sciences Gambat,

Khairpur Mirs Sindh.

Correspondence Address:

Dr. Hafiza Khatoon

Department of Obstetrics \&

Gynecology

PAQSJ Gambat Institute of Medica

Sciences Gambat,

Khairpur Sindh.

drhafizakhatoonpk@gmail.com

Article received on:

10/07/2020

Accepted for publication:

$08 / 09 / 2020$

\section{To assess the diagnostic accuracy of Color Doppler ultrasound in antenatal diagnosis of placenta accreta taking histopathology as gold standard.}

Farzana1, Hafiza Khatoon $^{2}$, Ambreen $\mathrm{Naz}^{3}$, Nousheen Mushtaq ${ }^{4}$, Safia ${ }^{5}$, Kanta Aahuja ${ }^{6}$

ABSTRACT... Objectives: To assess the diagnostic accuracy of color Doppler ultrasound in antenatal diagnosis of placenta accreta taking histopathology as gold standard. Study Design: Prospective study. Setting: Department of Obstetrics and Gynaecology, Gambat Institute of Medical Sciences Gambat, Khairpur Sindh. Period: 1st December 2018 to 30th June 2019. Material \& Methods: Women aged 20-45 years with previous history of placenta accrete and uterine scar were selected for the study. Informed consent was taken from women with placenta Previa and previous scar to undergo Doppler ultrasound. Results: A total of 115 patients participated in this study during one year time period. The mean age of e participants was found to be $33.71 \pm 5.61$ years. The mean gestational age was $35.24 \pm 2.7$ weeks. Out of total 115 cases, previous cesarean section was found in 48 (41.7\%) cases and previous history of placenta accreta was found in $9(7.8 \%)$ cases. Sensitivity of Color Doppler ultrasound in diagnosis of placenta accreta was $85.7 \%$ and specificity $96.6 \%$. Conclusion: There has always been a debate about the use of different modalities in detection of placenta accreta and its surgical management. Our study shows high sensitivity and specificity of color Doppler ultrasound in detection of placenta accreta. Large scale studies must be carried out on government level comparing the results of color Doppler and MRI and their outcomes.

Key words: $\quad$ Placenta Accreta, Color Doppler Ultrasound, Histopathology.

Article Citation: Farzana, Khatoon H, Naz A, Mushtaq N, Safia, Aahuja K. To assess the diagnostic accuracy of Color Doppler ultrasound in antenatal diagnosis of placenta accreta taking histopathology as gold standard. Professional Med J 2020; 27(12):2681-2685. https://doi.org/10.29309/TPMJ/2020.27.12.5553

\section{INTRODUCTION}

Placenta accreta is described as abnormal invasion and firm attachment of placenta on the uterine myometrium. According to level of invasion it is classified into three categories placenta accreta, percreta, and increta. It can also occur due to invasion of decidual layer into chorionic villi. From the beginning of 1990 the prevalence of placental invasion is increased due to increased ration of caesarean section from $5.8 \%$ in 1970 to $32.9 \%$ in $2009 .{ }^{1}$ The risk of developing placenta accreta rises proportionally from $0.3 \%$ to $0.6 \%, 2.1 \%, 2.3 \%, 6.7 \%$ after subsequent cesarean sections respectively. ${ }^{2}$ Placenta accreta poses a threat to life of fetus as well as the mother. Removal of placenta by traction in placenta accreta can lead to massive hemorrhage and it has been the most frequent indication for intrapartum hysterectomy. ${ }^{3}$ In previous studies mortality reported in mothers due to hemorrhage may go up to $7 \% .^{4}$ Thus antenatal detection of placenta accreta can provide benefit and decrease mortality. Globally, ultrasound and MRI imaging have been used widely as detection tool for placenta accreta. Diagnostic accuracy of ultrasound and MRI varies widely for placenta accreta. Findings of placenta accreta on ultrasound Color Doppler includes loss of the usual hypoechoic retro placental myometrium, thinning of uterine serosa-bladder interface, focal exophytic mass, thickness of myometrium greater than $1 \mathrm{~mm}$, high velocity turbulent flow in lacunae and increased vascularity proximal to bladder. ${ }^{5}$ The diagnostic criteria of placenta 
accreta on the basis of MRI includes abnormal uterine bulging, heterogeneous signal on T2weighted images, dark intraplacental bands on T2 weighted images, focal interruptions in the myometrial wall and direct visualization of the invasion of pelvic structures by placental tissue. ${ }^{6}$ Color Doppler ultrasound provides an opportunity for early and accurate diagnosis of placenta accrete with sensitivity of $86 \%$ and specificity of $96.8 \%$. Over the last decade the diagnostic modality for placenta accreta has changed and combination of investigations are used for placental abnormalities. Recently MRI has been the most useful investigation for accurate location and morphology. It is also required for treatment planning, surgical treatment and encountering future complications. ${ }^{7}$ As placenta accreta is a life threatening emergency and can lead to infertility, it should be investigated promptly to prevent morbidity and mortality. Previous study conducted in Multan in year 2013 for diagnostic accuracy of color Doppler ultrasound for morbidly adherent placenta sensitivity and specificity was found to be $87.5 \%$ and $98.36 \%$ respectively. ${ }^{8}$ In most of the cases, morbidly adherent placenta on surgical removal has been detected on ultrasound color Doppler. Few false negative placenta accreta cases are also detected which on cesarean section don't have adherent placenta in the myometrium. ${ }^{9}$ The aim of our study is to assess the diagnostic accuracy of color Doppler ultrasound in antenatal diagnosis of placenta accrete taking histopathology as gold standard."

\section{MATERIAL \& METHODS}

This is a prospective study carried out at Gynecology and Obstetrics Department of Obstetrics and Gynaecology, Gambat Institute of Medical Sciences Gambat, Khairpur Sindh, from 1st December 2018 to 30th June 2019. Participants of the study included were pregnant women of gestational age between 30-38 weeks calculated via trimester scan. Women aged 2045 years with previous history of placenta accrete and uterine scar were selected for the study. Women unfit for anesthesia and no previous uterine scar were excluded from the study. All women who were registered through OPD as booked cases were made part of the study.
Informed consent was taken from women with placenta Previa and previous scar to undergo Doppler ultrasound. The presence of diffuse and focal parenchymal placental lacunar flow, bladderuterine serosa interphase hyper vascularity, prominent sub placental venous complex, and loss of sub placental Doppler vascular findings were confirmed. Ultrasound was done by consultant sonologist having greater than15yrs of experience. Data was collected using a proforma which included sociodemographic information along with complete medical information from all candidates. All efforts were made by researcher to ensure that complete data was collected. Analysis was done by SPSS version 20 to evaluate frequency of placenta accreta detection by color Doppler ultrasound."

\section{RESULTS}

A total of 115 patients were enrolled in this study during one year time period. The mean age of enrolled participants was found to be 33.71 \pm 5.61 years (20 to 45 years). The mean gestational age was $35.24 \pm 2.7$ weeks (Upto 39 weeks). Out of total 115 cases, previous cesarean section was found in 48 (41.7\%) cases as shown in Table-I and previous history of placenta accreta was found in $9(7.8 \%)$ cases. Placenta accreta was diagnosed on Color Doppler Ultrasound in $48.7 \%(n=56)$ cases, whereas placenta accreta was diagnosed by histopathology in $52.2 \%(n=60)$ of women as shown in Table-I.

Sensitivity of Color Doppler ultrasound in diagnosis of placenta accreta was $85.7 \%$, specificity $96.6 \%$, positive predictive value $96 \%$ and negative predictive value: $87.7 \%$ (Table-II). Diagnostic accuracy of color Doppler ultrasound in different parameters (Table-III)."

\begin{tabular}{|l|c|c|}
\hline \multicolumn{1}{|c|}{ Variable } & Frequency & Percent \\
\hline Cesarean Section & & \\
\hline Yes & 48 & $41.7 \%$ \\
\hline No & 67 & $58.3 \%$ \\
\hline History of Placenta Accreta & \\
\hline Yes & 9 & $7.8 \%$ \\
\hline No & 106 & $92.2 \%$ \\
\hline Investigation for Diagnosis of Placenta Accreta \\
\hline Color Doppler & 56 & $48.7 \%$ \\
\hline Histopathology & 60 & $52.2 \%$ \\
\hline \multicolumn{2}{|c|}{ Table-I. Different variable } \\
\hline
\end{tabular}




\begin{tabular}{|l|c|c|c|c|}
\hline & \multicolumn{3}{|c|}{ Histopathology } & \\
\hline & & Yes & No & Total \\
\hline \multirow{2}{*}{$\begin{array}{l}\text { Color Doppler } \\
\text { Ultrasound }\end{array}$} & Yes & 48 & 2 & 50 \\
\cline { 2 - 5 } & No & 8 & 57 & 65 \\
\hline & Total & 56 & 59 & 115 \\
\hline
\end{tabular}

Table-II. Diagnostic accuracy of color Doppler Ultrasound

Sensitivity: $85.7 \%$

Specificity: $96.6 \%$

Positive predictive value: $96 \%$

Negative predictive value: $87.7 \%$

\begin{tabular}{|l|c|c|c|c|}
\hline Parameters & Sensitivity & Specificity & PPV & NPV \\
\hline Age \\
\hline$<35$ years & $88.2 \%$ & $93.9 \%$ & $93.8 \%$ & $88.6 \%$ \\
\hline$\geq 35$ years & $81.8 \%$ & $100 \%$ & $100 \%$ & $86.7 \%$ \\
\hline Gestational age \\
\hline$<35$ years & $100 \%$ & $96.2 \%$ & $95 \%$ & $100 \%$ \\
\hline$\geq 35$ years & $74.2 \%$ & $97 \%$ & $95.8 \%$ & $80 \%$ \\
\hline History of cesarean section \\
\hline Yes & $93.3 \%$ & $90 \%$ & $94 \%$ & $100 \%$ \\
\hline No & $71.4 \%$ & $100 \%$ & $100 \%$ & $83 \%$ \\
\hline History of placenta accrete \\
\hline Yes & $100 \%$ & $90 \%$ & $66.7 \%$ & $60 \%$ \\
\hline No & $84.6 \%$ & $100 \%$ & $100 \%$ & $87.1 \%$ \\
\hline
\end{tabular}

\section{DISCUSSION}

Color Doppler ultrasound has been the most frequently used investigation by gynecologist in identifying the location of placenta. It is a low cost and easily available modality but the results are experienced based. In contrast to MRI which is expensive and cannot be made available throughout the country. The need for diagnostic accuracy of color Doppler thus raises a question whether it is beneficial in the timely management of patients. ${ }^{10}$ Previous study in Multan, the ratio of morbidly adherent placenta was found in $11.59 \%$ of patients with color Doppler ultrasound. During antenatal checkups the sensitivity and specificity of color Doppler was found to be $87.5 \%$ and $98.36 \%$, with positive predictive value of $98.36 \% .^{8}$
Other researches have also shown that the diagnostic accuracy of color Doppler ultrasound ranges from $82.4 \%$ and $100 \%$, and $91.2 \%$ specificity between $92 \%$ and $96.8 \% .^{11}$ In our study the sensitivity of total 115 participants was $85.7 \%$ and a specificity of $96.6 \%$. The sensitivity of color Doppler ultrasound varies according to the age of pregnant female as in our study after stratification according to age $>35$ years and $<35$ years old women. In women aged <35years the sensitivity is $88.2 \%$ and in women aged $>35$ years the sensitivity has dropped down to $81.8 \%$. In contrast to the specificity this ranges from $93.9 \%$ to $100 \%$ in different age groups. The expected prevalence of using color Doppler in detection of morbidly adherent placenta is found to be $82 \% .^{12}$ The lower anterior segment of uterus is the most common location for placenta accreta and it color Doppler is easier to identify due to its superficial location with bladder interface. In some studies it has been used to differentiate placenta accreta from placenta percreta. ${ }^{13}$ The risk of placenta accreta increases with rising number of lacunae, as all cases of placenta accreta have minimum four lacunae. After 15 weeks of gestation lacunae are present so that it can be detected by color Doppler. ${ }^{14}$ Placenta accreta has been detected by turbulent blood flow in placental lacunae and was almost present in every case. Previous study showed that color Doppler ultrasound sensitivity was $83 \%$, its specificity was $95 \%$ as compared to sensitivity and specificity of MRI which is $82 \%$ and $88 \%$ respectively." Color Doppler has been found to have high sensitivity and specificity for detection of morbidly adherent placenta, so this modality is recommended for use in management. It is more cost effective and easily accessible modality for use by gynecologist. ${ }^{15}$ The investigation of choice for placenta accreta has always remained a question as the sensitivity varies widely over different studies. The sensitivity of color Doppler ultrasound varies from 33\% to $100 \%$ depending in the expertise of sonologist and reporting. ${ }^{16}$ In developed countries MRI with gadolinium staining has been used to improve outcomes of the baby and mother. A large scale study and few case series have been pointing towards the utilization of MRI in management of placenta accrete. ${ }^{17}$ 


\section{CONCLUSION}

There has always been a debate about the use of different modalities in detection of placenta accreta and its surgical management. Our study shows high sensitivity and specificity of color Doppler ultrasound in diagnosing placenta accreta. Large scale studies must be carried out on government level comparing the results of color Doppler and MRI and their outcomes.

Copyright@ 08 Sep, 2020.

\section{REFRENCES}

1. Blanchette $H$. The rising cesarean delivery rate in America: What are the consequences?. Obstetrics \& Gynecology. 2011 Sep 1; 118(3):687-90.

2. Meng $X$, Xie L, Song W. Comparing the diagnostic value of ultrasound and magnetic resonance imaging for placenta accreta: A systematic review and metaanalysis. Ultrasound in medicine \& biology. $2013 \mathrm{Nov}$ 1; 39(11):1958-65.

3. Zelop CM, Harlow BL, Frigoletto FD Jr, Safon LE, Saltzman DH. Emergency peripartum hysterectomy. Am J Obstet Gynecol 1993; 168: 1443-1448.

4. O'Brien JM, Barton JR, Donaldson ES. The management of placenta percreta: Conservative and operative strategies. American journal of obstetrics and gynecology. 1996 Dec 1; 175(6):1632-8.

5. Dwyer BK, Belogolovkin V, Tran L, Rao A, Carroll I, Barth R, Chitkara U. Prenatal diagnosis of placenta accreta: Sonography or magnetic resonance imaging?. Journal of Ultrasound in Medicine. 2008 Sep; 27(9):1275-81.

6. Baughman WC, Corteville JE, Shah RR. Placenta accreta: Spectrum of US and MR imaging findings. Radiographics. 2008 Nov; 28(7):1905-16.

7. Mazouni C, Gorincoue G, Johan V, Bretelle F. Placenta accrete: $A$ review of current advances in prenatal diagnosis. Placenta 2007; 28:599-603.

8. Khalid D, Noreen A, Javed AM, Zahra M, Gul M, Shakir A. Diagnostic accuracy of Color Doppler ultrasound in antenatal diagnosis of morbidly adherent placenta, taking operative findings of cesaerean section as gold standard. Pakistan Journal of Medical and Health Sciences. 2016 Apr 1; 10(2):478-81.
9. Lim PS, Greenberg M, Edelson MI, Bell KA, Edmonds PR, Mackey AM. Utility of Ultrasound and MRI in prenatal diagnosis of placenta accreta. Am J Roentgenol. 2011; 197:1505-13.

10. Elhawary TM, Dabees NL, Youssef MA; Diagnostic value of ultrasonography and magnetic resonance imaging in pregnant women at risk for placenta accreta. J Matern Fetal Neonatal Med. 2013; 26(14):1443-9.

11. Thai EW, Lee SL, Tan HK. Ultrasonographical features of morbidly-adherent placentas. Singapore Med J. 2007; 48(9):799-802.

12. Warshak CR, Eskander R, Hull AD. Accuracy of ultrasonography and magnetic resonance imaging in the diagnosis of placenta accreta. Obstet Gynecol. 2006; 108:573-81.

13. Calì G, Giambanco L, Puccio G, Forlani F. Morbidly adherent placenta: Evaluation of ultrasound diagnostic criteria and differentiation of placenta accreta from percreta. Ultrasound Obstet Gynecol. 2013; 41(4):406-12.

14. Yang JI, Lim YK, Kim HS, Chang KH, Lee JP, Ryu HS. Sonographic findings of placental lacunae and the prediction of adherent placenta in women with placenta previatotalis and prior Cesarean section. Ultrasound Obstet Gynecol. 2006; 28:178-82.

15. Maher MA, Abdelaziz A, Bazeed MF. Diagnostic accuracy of ultrasound and MRI in the prenatal diagnosis of placenta accreta. Acta Obstet Gynecol Scand. 2013; 92:1017-22.

16. Lam G, Kuller J, McMahon M. Use of magnetic resonance imaging and ultrasound in the antenatal diagnosis of placenta accreta. J Soc Gynecollnvestig 2002; 9:37-40.

17. Lax A, Prince MR, Mennitt KW, Schwebach JR, Budorick NE. The value of specific MRI features in the evaluation of suspected placental invasion. MagnReson Imaging 2007; 25:87-93. 


\section{AUTHORSHIP AND CONTRIBUTION DECLARATION}

\begin{tabular}{|c|c|c|c|}
\hline Sr. \# & Author(s) Full Name & Contribution to the paper & Author(s) Signature \\
\hline 1 & Farzana & $\begin{array}{l}\text { Conception and design, Statistical } \\
\text { expertise, Critical revision of the } \\
\text { article for important intellectual } \\
\text { content. }\end{array}$ & \\
\hline 2 & Hafiza Khatoon & $\begin{array}{l}\text { Data collection, Critical revision of } \\
\text { the article for important intellectual } \\
\text { content. }\end{array}$ & $A R$ \\
\hline 3 & Ambreen Naz & $\begin{array}{l}\text { Data collection, Critical revision, } \\
\text { Drafting of the article. }\end{array}$ & \\
\hline 4 & Nousheen Mushtaq & Data collection. & \\
\hline 5 & Safia & Data collection & \\
\hline 6 & Kanta Aahuja & Data collection & \\
\hline
\end{tabular}

